Article

\title{
Comparison of Various Easy-to-Use Procedures for Extraction of Phenols from Apricot Fruits
}

\section{Ondrej Zitka ${ }^{1}$, Jiri Sochor ${ }^{1}$, Otakar Rop ${ }^{2}$, Sylvie Skalickova ${ }^{1}$, Pavlina Sobrova ${ }^{1}$, Josef Zehnalek $^{1}$, Miroslava Beklova ${ }^{3}$, Boris Krska ${ }^{4}$, Vojtech Adam ${ }^{1}$ and Rene Kizek ${ }^{1, *}$}

1 Department of Chemistry and Biochemistry, Faculty of Agronomy, Mendel University in Brno, Zemedelska 1, CZ-613 00 Brno, Czech Republic

2 Department of Food Technology and Microbiology, Faculty of Technology, Tomas Bata University in Zlin, Namesti T. G. Masaryka 275, CZ-762 72 Zlin, Czech Republic

3 Department of Veterinary Ecology and Environmental Protection, University of Veterinary and Pharmaceutical Sciences, Palackeho 1-3, CZ-61242 Brno, Czech Republic

4 Department of Fruit Growing, Faculty of Horticulture, Mendel University in Brno, Zemedelska 1, CZ-613 00 Brno, Czech Republic

* Author to whom correspondence should be addressed; E-Mail: kizek@sci.muni.cz; Tel.: +420-5-4513-3350; Fax: +420-5-4521-2044.

Received: 9 March 2011; in revised form: 25 March 2011 / Accepted: 31 March 2011 / Published: 4 April 2011

Abstract: Phenols are broadly distributed in the plant kingdom and are the most abundant secondary metabolites of plants. Plant polyphenols have drawn increasing attention due to their potential antioxidant properties and their marked effects in the prevention of various oxidative stress associated diseases such as cancer. The objective of this study was to investigate a suitable method for determination of protocatechuic acid, 4-aminobenzoic acid, chlorogenic acid, caffeic acid, vanillin, $p$-coumaric acid, rutin, ferulic acid, quercetin, resveratrol and quercitrin from apricot samples. A high-performance liquid chromatograph with electrochemical and UV detectors was used. The method was optimized in respect to both the separation selectivity of individual phenolic compounds and the maximum sensitivity with the electrochemical detection. The lowest limits of detection $(3 \mathrm{~S} / \mathrm{N})$ using UV detection were estimated for ferulic acid $(3 \mu \mathrm{M})$, quercitrin $(4 \mu \mathrm{M})$ and quercetin (4 $\mu \mathrm{M})$. Using electrochemical detection values of $27 \mathrm{nM}, 40 \mathrm{nM}$ and $37 \mathrm{nM}$ were achieved for ferulic acid, quercitrin and quercetin, respectively. It follows from the acquired results that the coulometric detection under a universal potential of $600 \mathrm{mV}$ is 
more suitable and sensitive for polyphenols determination than UV detection at a universal wavelength of $260 \mathrm{~nm}$. Subsequently, we tested the influence of solvent composition, vortexing and sonication on separation efficiency. Our results showed that a combination of water, acetone and methanol in 20:20:60 ratio was the most effective for p-aminobenzoic acid, chlorgenic acid, caffeic acid, protocatechuic acid, ferulic acid, rutin, resveratrol and quercetin, in comparison with other solvents. On the other hand, vortexing at $4{ }^{\circ} \mathrm{C}$ produced the highest yield. Moreover, we tested the contents of individual polyphenols in the apricot cultivars Mamaria, Mold and LE-1075. The major phenolic compounds were chlorgenic acid and rutin. Chlorgenic acid was found in amounts of 2,302 mg/100 g in cultivar LE-1075, $546 \mathrm{mg} / 100 \mathrm{~g}$ in cultivar Mamaria and $129 \mathrm{mg} / 100 \mathrm{~g}$ in cultivar Mold. Generally, the cultivar LE-1075 produced the highest polyphenol content values, contrary to Mold, which compared to cultivar LE-1075 was quite poor from the point of view of the phenolics content.

Keywords: polyphenols; apricot; high performance liquid chromatography; CoulArray electrochemical detector; UV-VIS detector

\section{Introduction}

Nowadays the lifestyle trend is to consume a diet rich in fresh fruit and vegetables beneficial to our health. Fresh products are rich in various nutrients such as fiber, vitamins, minerals, organic substances and finally phenolic compounds. Phenolic compounds are a large class of naturally occurring compounds generally synthesized via the shikimate pathway. Another pathway, the polyketide pathway, can also provide some phenols, e.g., orcinols and quinones. Phenolic compounds derived from both pathways are quite common, e.g., flavonoids, stilbenes, pyrones and xanthones [1]. Polyphenols are widely present in plants have a wide range of functions [2-4]. They protect them from oxidative stress, UV light, pathogens, eating by herbivores, lignans form a mechanical reinforcement of the plant body and others can play a role as cell signalling molecules [5-8]. In humans and animals they prevent common diseases, including coronary diseases, cancer, neurodegenerative diseases, gastrointestinal disorders and others [9]. Other authors have described how polyphenols affect endothelial function and as a consequence, blood pressure [10]. A basic scheme of polyphenols properties is shown in Figure 1. This is the reason that polyphenols have attracted great interest in the functional foods, nutraceutical and pharmaceutical industries. They are used as aromatic, tastesupplying and colouring substances, although the unpleasant taste of most phenolic compounds limits their applications [11]. On the other hand, the toxicity of simple phenols was demonstrated [12,13]. Experimental studies of the "extended toxicity" of substituted phenols are mainly of two types: the toxicity due to phenoxyl radical formation and the toxicity caused by metabolites, for example, the formation of quinones [14]. Quinones also play a major role in allergic contact dermatitis caused by plants. The principal allergens are benzoquinones or naphthoquinones but also compounds, such as catechols and other phenolic or flavonoid compounds, which are bioconverted into ortho-quinones or para-quinones [15]. 
Figure 1. Polyphenols and their biological properties. Polyphenols have a great variety of beneficial effects like anticarcinogenic (e.g., quercetin, protocatechuic acid) antiallergic (e.g., rosmarinic acid, curcumin), antiinflammatory (e.g., cathechin, resveratrol), antiproliferative (e.g., chlorgenic acid, caffeic acid, resveratrol), antiviral (e.g., aminobenzoic acid, p-coumaric) and antioxidant (e.g., rutin, chlorgenic acid, quercetin on human health. Their antioxidant properties and abilities to modulate several enzymes are also important. Some flavonoids have also mutagenic (e.g., quercetin) and/or prooxidant effects (e.g., caffeic acid) and they may interfere with essential biochemical pathways.

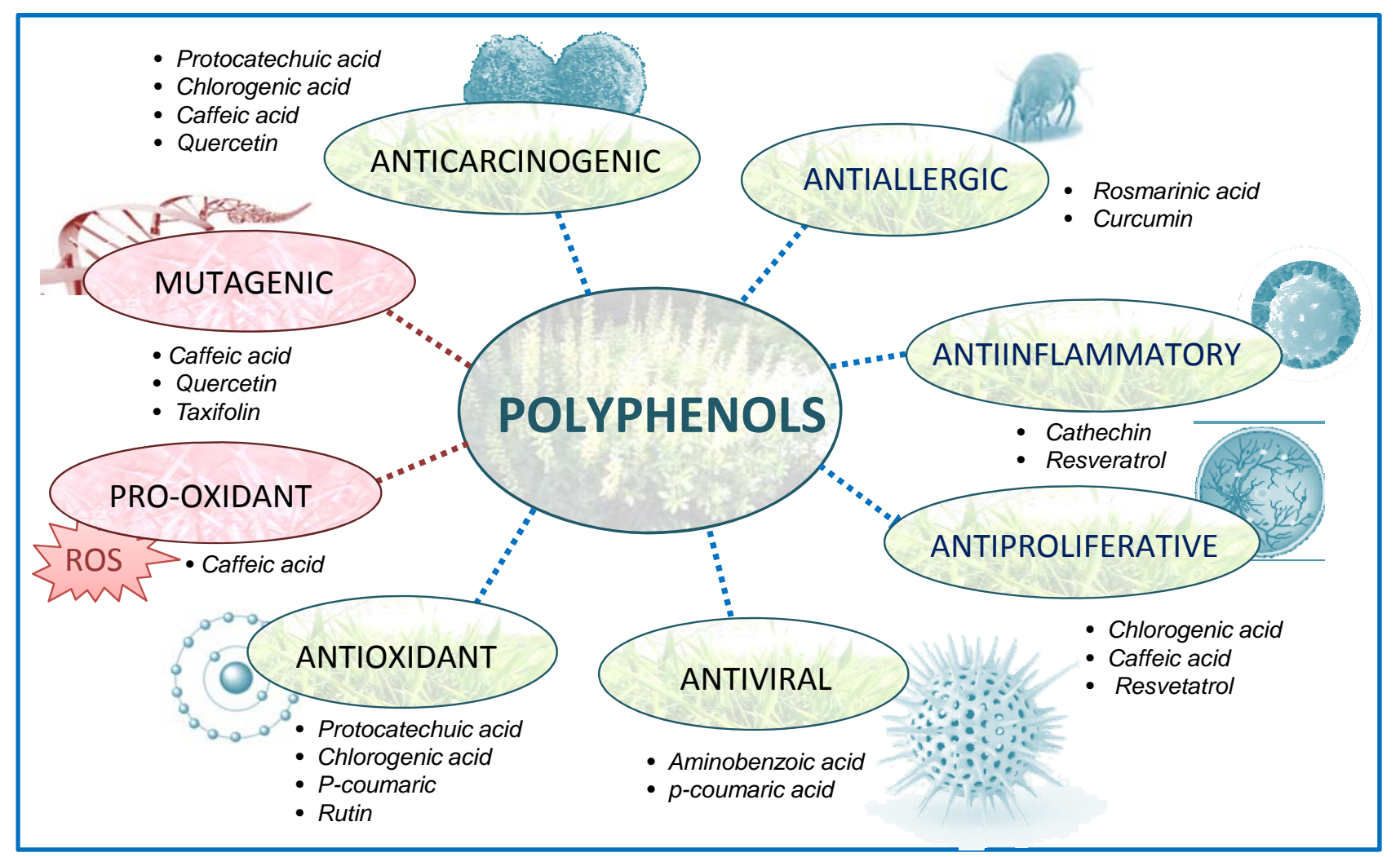

\subsection{Representative polyphenols}

\subsubsection{Protocatechuic acid (3,4-dihydroxybenzoic acid, PCA)}

Protocatechuic acid (PCA) present in natural products (in plants and fruits), is also a catabolite of epinephrine. The efficiency of PCA as a strong anti-radical, antioxidant and moderate scavenger of $\mathrm{H}_{2} \mathrm{O}_{2}$, has been widely reported. Its free-radical scavenging ability inhibits chemical carcinogenesis and protects against hydroperoxide-induced toxicity [16,17]. Many studies based on animal experiments have shown that PCA has strong anti-cancer effects [18,19]. In addition strong neuroprotective effects have been demonstrated [20].

\subsubsection{4-Aminobenzoic acid (PABA)}

PABA is a cyclic amino acid belonging to the vitamin B group and is used as a protective drug against solar insolation and in diagnostic tests for the state of the gastrointestinal tract in medicine [21]. PABA occurrence in plant and animal tissues have been determined [22]. PABA is an inducer 
of endogenous interferon and immunomodulator and displays a virucidal, synergistic antiviral effect when combined with chemical drugs and the properties of a direct anticoagulant [21]. Other studies described anti-virulent properties and therapeutic effect against typhoid and rickettsias diseases [23].

\subsubsection{Chlorogenic acid [3-(3,4-dihydroxycinnamoyl)quinate]}

Chlorogenic acid is structurally an ester of polyphenolic caffeic acid and cyclitol L-quinic acid [24]. It is an important intermediate in lignin biosynthesis [25]. It is also an antioxidant [26] and can contribute to treatment of atherosclerosis and ischemic reperfusion illnesses [27]. Other authors have described the properties of chlorogenic acid as an inhibitor of tumour promoting activity [28]. Moreover, chlorogenic acid decreases the cholesterol level in the blood of alcoholics by stimulation of secretion of bile acids [29].

\subsubsection{Caffeic acid [3-(3,4-dihydroxyphenyl 2-propenoic acid]}

Caffeic acid is a key intermediate in the biosynthesis of lignin, one of the principal sources of biomass. It presents antioxidant effects in vitro and might therefore contribute to the prevention of cardiovascular disease [30]. Caffeic acid is a hydroxycinnamic acid derivative that is widely distributed in plant-derived food products [24]. Studies indicate that some dietary compounds may have concentration-dependent antioxidant or pro-oxidant activities [31]. Caffeic acid also inhibits the production of carcinogenic and mutagenic N-nitrosation compounds [32] and protects from DNA damages in vitro [33,34].

\subsubsection{Vanillin (4-hydroxy-3-methoxybenzaldehyde)}

Vanillin is most prominent as the principal flavour and aroma compound in vanilla that is abundantly used in the food industry. Vanillin decreases the incidence of large intestinal carcinomas [35]. Vanillin also considerably suppresses bacterial formation [36]. The ability of vanillin inhibiting photosensitization-induced single-strand breaks in plasmid pBR322 DNA has been examined in an in vitro system, independent of DNA repair/replication processes [37]. Therefore, interaction of singlet oxygen with vanillin was investigated $[37,38]$.

\subsection{6. p-Coumaric acid (3-(4-hydroxyphenyl)-2-propenoic acid)}

Coumaric acid is a hydroxy derivative of cinnamic acid [39]. p-Coumaric acid has antioxidant properties and in peroxidising lipid systems mediated by metamyoglobin [40]. Moreover, the antioxidant effects of LDL cholesterol have been demonstrated so it also prevents atherosclerosis [41]. It is believed to reduce the risk of stomach cancer by reducing the formation of carcinogenic nitrosamines [40].

\subsubsection{Rutin}

Rutin is an antioxidant with many interesting pharmacological effects. There is an evidence that rutin protects plants against UV radiation by activation of enzymes of the phenylpropanoid pathway $[42,43]$. Rutin exerts renal protective effects, probably by inhibiting ROS and antioxidant activities 
[44]. Positive effects of rutin on human health are primarily in decreasing of blood pressure [45], decreasing of permeability of blood vessels and swelling creation and thus prevent atherosclerosis [46].

\subsubsection{Ferulic acid [(E)-3-(4-hydroxy-3-methoxyphenyl)prop-2-enoic acid]}

Ferulic acid (FA), like many phenols, has concentration-dependent antioxidant effects in terms of inhibition of lipid peroxidation and reactive oxygen species [31]. Moreover, the photoprotective properties of FA on human keratinocytes help to prevent damage by ultraviolet (UV) radiation and skin carcinogenesis, have been described [47,48]. The effects of FA on the proliferation of neural stem/progenitor cells (NSC/NPCs) in vitro and in vivo was investigated [49].

\subsubsection{Quercetin}

Quercetin is a dietary polyphenolic compound with potentially beneficial effects on health [50]. Numerous studies confirmed quercetin's properties as an antioxidant [51,52]. Quercetin can quench reactive oxygen species and protect the organism from pro-oxidative damage [53]. Quercetin also protects the organism against coronary diseases [54,55], lung cancer and asthma [56]. An in vitro study investigated the possible radioprotective effects of the natural substances propolis and quercetin on gamma-irradiated human white blood cells [57].

\subsubsection{Resveratrol}

In recent years, resveratrol has become a popular nutritional supplement used by humans all over the world. Detailed research has been conducted to determine the efficacy of its use both in preventive and therapeutic dimensions [58]. Resveratrol, with its known potency and wide variety of health benefits, has shown promising results in minimizing cardiovascular complications [59] including hypertension [60] and it reduces oxidative organ damage in the renal system [61], hypertrophy [62], ischemic heart disease and atherosclerosis [63]. However, a great deal of controversy exists regarding the use of resveratrol as an anti-aging compound [64].

\subsubsection{Quercitrin}

Quercitrin is a glycoside formed from the flavonoid quercetin and the deoxy sugar rhamnose. It is a constituent of the dye quercitron. It is widely distributed in many edible (Qi 1) [65] and medicinal (Qi 2) plants [66], and exhibits a wide range of biological activities, such as antioxidant [67], inhibition of acetylcholinesterase [66] and serine/threonine kinase pim-2 [68], hepatoprotection [69], and antimalarial activities [70]. Recently, the anti-HIV and cytotoxic activities [71] against human oral tumour cell lines were reported.

\subsection{Extraction}

The extraction of phenolic compounds is one of the stages in the sample preparation process [72]. Numerous methods such as microwave, ultrasound-assisted extractions, and techniques based on use of compressed fluids such as subcritical water extraction (SWE), supercritical fluid extraction (SFE), pressurized fluid extraction (PFE) or accelerated solvent extraction (ASE) as extracting agents, have 
been developed in recent years for the extraction of phenolic compounds from plant materials [72]. The effect of extraction conditions on polyphenols has been a contentious issue, particularly when comparing different raw materials. Many factors such as chemical nature, solvent composition, extraction time, extraction temperature, and solvent to solid ratio may significantly influence the extraction efficacy and yield [14]. The chemical nature of plant phenols vary from simple to highly polymerized substances that include varying proportions of phenolic acids, phenylpropanoids, anthocyanins and tannins, among others. They may also exist as complexes with carbohydrates, proteins and other plant components; some high-molecular-weight phenols and their complexes may be quite insoluble. Therefore, phenolic extracts of plant materials are always a mixture of different classes of phenols that are soluble in the solvent system used. Additional steps may be required for the removal of unwanted phenolics and non-phenolic substances such as waxes, fats, terpenes and chlorophylls [73,74]. Solid phase extraction (SPE) techniques and fractionation based on acidity are commonly used to remove unwanted phenolics and non-phenolic substances [14]. Solubility of phenolic compounds is governed by the type of solvent (polarity) used. The commonly used types of solvent for extracting polyphenols are methanol, ethanol, acetone, and their water solutions [75]. Thus, alcoholic solvents have been commonly employed to extract phenolics from natural sources, because they give relatively high yield of total extract, even though they are not highly selective for phenols. Particularly, mixtures of alcohols and water have revealed to be more efficient in extracting phenolic constituents than the corresponding mono-component solvent systems [76]. Using water as a solvent does not achieve high efficiency of extraction because some molecules contain sugars in their structure, which are soluble in water [75].

Moreover, the extraction depends on the duration of the solvent's influence on the substrate containing phenolic compounds. It hab been reported, that extraction periods usually varying from 1 $\min$ to $24 \mathrm{~h}$ [77]. Longer extraction times increase the chance of oxidation of phenolics unless reducing agents are added to the solvent system [78]. Extraction temperature is one of the important factors affecting the extraction rate of polyphenols. At higher temperature, a higher yield of polyphenols extracted from fruit can be obtained. High-temperature solvents will promote polysaccharides in cell walls to distribute to solvent, and to weaken or undermine the integrity of the cell wall, thus, more polyphenols can be dissolved in the solvent used. All of these factors allow both to determine individual components and to obtain the characteristic patterns of real samples [76].

\subsection{Analysis of polyphenols}

Spectroscopy, chromatography and electrophoresis are the main methods used for polyphenols determination. Spectroscopic methods are useful only for the determination of large amounts of polyphenol compounds in a sample. Investigations devoted to this problem using HPLC with UV detection are the most numerous [75]. Although less used in analysis, since the early 1960s, thin-layer chromatography has been in vogue in phenolic analysis and still plays a distinct role in the determination of phenols in natural products $[74,79]$. It is especially useful for the rapid screening of plant extracts for pharmacologically active substances prior to detailed analysis. In the last twenty years, HPLC has been the analytical technique that has dominated the separation and characterisation of phenolic compounds. Due to the relatively high-molecular mass and intrinsic features 
of hydrophobic flavonoid aglycones and hydrophilic flavonoid glycosides, the overwhelming majority of chromatographic methods in the literature fall in the realm of HPLC and related technologies. HPLC techniques offer a unique chance to separate simultaneously all analysed components together with their possible derivatives or degradation products. In many cases, they enable the determination of low concentrations of analytes in the presence of many other interfering and coeluting components. There are many advantages dictating the widespread use of HPLC in the analysis of phenolic compounds in plant-derived and biological matrices, such as: (i) the wide range of commercially available columns, including those using new generation sorbents with fit for-purpose properties and (ii) the possibility of combining two or more columns in a switching mode [73].

Phenolics are commonly detected using ultraviolet/visible (UV/VIS), photodiode array (PDA), and UV-fluorescence detectors [80-82]. Other methods used for the detection of phenolics include electrochemical coulometric array detection, on-line connected PDA and electroarray detection, chemical reaction detection techniques, mass spectrometric and nuclear magnetic resonance detection [83-85]. It is evident that phenolics absorb well in the UV range and UV detection is therefore a convenient method to localise a phenol in the effluent of a column. However, no single wavelength is sufficient for their simultaneous monitoring in various natural plant extracts. Therefore, electrochemical detection provides a high selectivity and sensitivity, thus laborious sample pretreatments such as extraction, purification or concentration are not necessary [86].

The objective of this study was to determine protocatechuic acid, 4-aminobenzoic acid, chlorogenic acid, caffeic acid, vanillin, $p$-coumaric acid, rutin, ferulic acid, quercetin, resveratrol and quercitrin from apricot using HPLC with electrochemical and UV detector and compare their sensitivity for chosen substances. Moreover, the solvent composition and influence of conditions of extraction efficiency were tested.

\section{Results and Discussion}

\subsection{Optimization of electrochemical detection}

Primarily, we optimized detection potential as the fundamental parameter for HPLC-ED measurements. The applied potential of electrochemical detector was changed within the range from 100 to $900 \mathrm{mV}$. The measurement step between each potential was $100 \mathrm{mV}$. All compounds were measured under each potential three times for calculation of RSD, which was lower than $4.5 \%$. Stock solutions of all standards $(1 \mathrm{~mL})$ were arranged in an autosampler and cooled at $8{ }^{\circ} \mathrm{C}$. Analysis of each injection took 1 minute. The measured signal from the electrochemical detector represented oxidative behaviour of the single molecule under each of tested potentials. After collecting of the data we used them for various interpretations of hydrodynamic voltammograms. To select a potential for simultaneous determination of phenols, heights of signals measured under each potential were summed and are shown in Figure 2A. Behaviour of the analytes differed markedly within the tested range of potentials. Only six analytes gave a detectable signal at $100 \mathrm{mV}$. The highest signal of 4-aminobenzoic acid, chlorogenic acid, caffeic acid was detected at a potential of $400 \mathrm{mV}$, vanillin and ferulic at $500 \mathrm{mV}$, protocatechuic acid and resveratrol at $600 \mathrm{mV}, p$-coumaric acid at $700 \mathrm{mV}$ and rutin, quercetin and quercitrin at $800 \mathrm{mV}$. Due to the highest sum of signals, the most suitable and versatile potential of detection was determined to be $600 \mathrm{mV}$. The other reason why this potential was 
selected is that measurement using lower potentials did not detect any signal for protocatechuic acid. This is a consequence of compromise that no substance from the group is in single potential significantly discriminated. We used this potential for determination of polyphenols in apricots. Structure of measured polyphenols is shown in Figure 2B.

Figure 2. (a) Electrochemical response of applied potential on peak areas. Sum of peak areas show that the highest yield of extraction was at $600 \mathrm{mV}$ potential. Areas of single peak of polyphenols show their extraction efficiency. Low potential did not provide protocatechuic acid detection. (b) Chemical structures of chosen polyphenols.

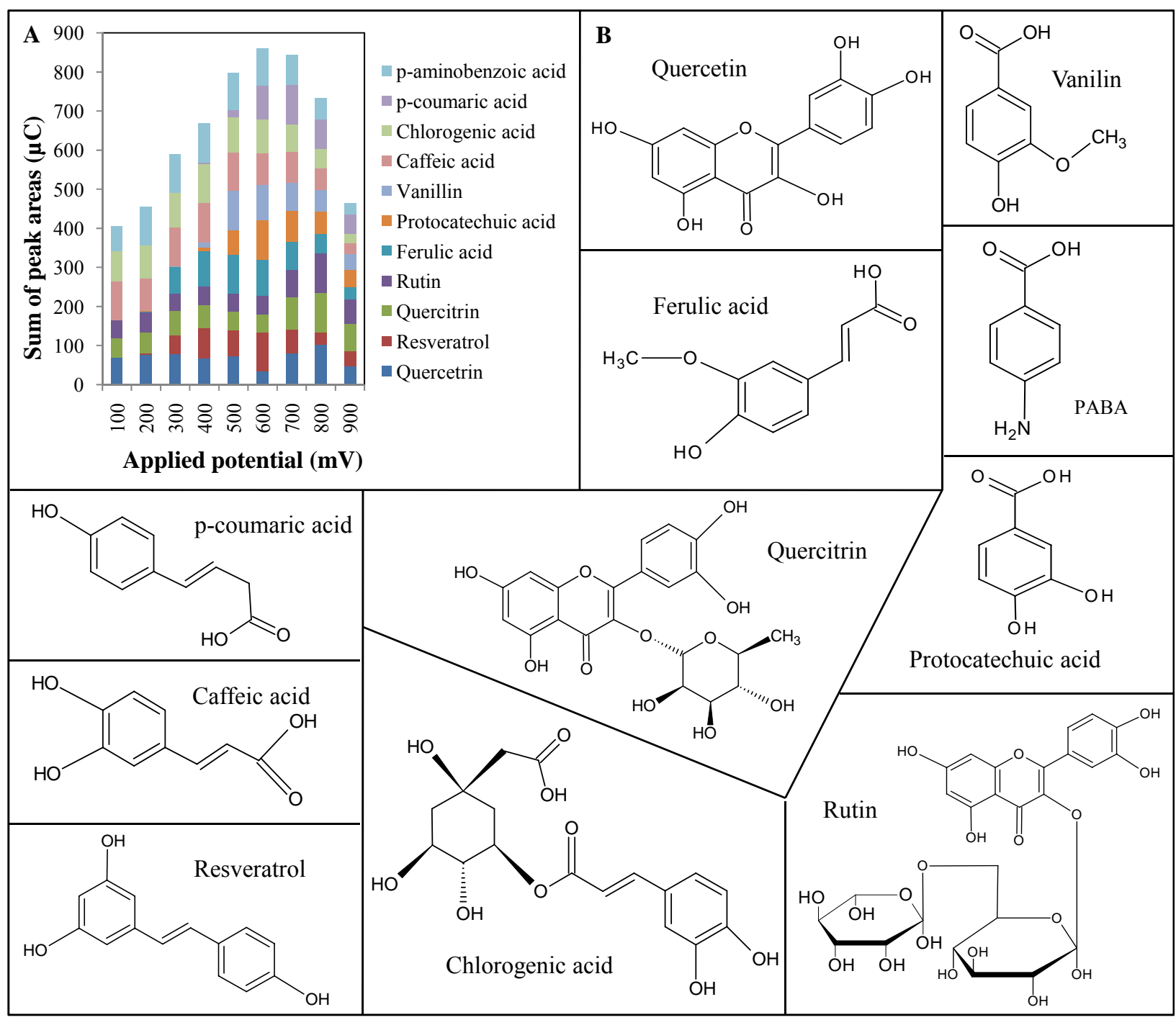

\subsection{Comparison of UV and ED}

UV and electrochemical detector were coupled. UV detector was chosen as the first one due to the fact that it is not destructive. The highest concentration $100 \mu \mathrm{g} / \mathrm{mL}$ and subsequent dilution with water in ratio $1: 1$ of the previous concentration were prepared for constructions of calibration dependencies. The resulting analytical parameters of UV detection are shown in Table 1. Coefficients of determination of calibration curves showed good linearity. The lowest limits of detection $(3 \mathrm{~S} / \mathrm{N})$ were estimated for ferulic acid $(3 \mu \mathrm{M})$, quercitrin $(4 \mu \mathrm{M})$ and quercetin $(4 \mu \mathrm{M})$. Analytical parameters 
of electrochemical detection show a similar trend in the linearity of coefficients of determination of calibration curves. However, the detection limits are lowered by two orders of magnitude than for UV detection (Table 2). Using electrochemical detector LOD values of $27 \mathrm{nM}, 40 \mathrm{nM}$ and $37 \mathrm{nM}$ were reached for ferulic acid, quercitrin and quercetin, respectively. The marked difference in the sensitivity of both detectors is evident in comparison of chromatograms of both detection techniques (Figure 3).

Figure 3. (a) The HPLC-UV chromatogram for determination phenolic compounds. Absorbance shows the quantity of particular substances in samples. (b) Dependence of peak area $(\mathrm{mAU} / \mathrm{s})$ on concentration $(\mu \mathrm{g} / \mathrm{g})$ and of single phenols. (c) The HPLC-ED chromatogram for determination of phenolic compounds. (c) Dependence of concentration $(\mu \mathrm{g} / \mathrm{g})$ and peak area $(\mu \mathrm{C})$ of single phenols.

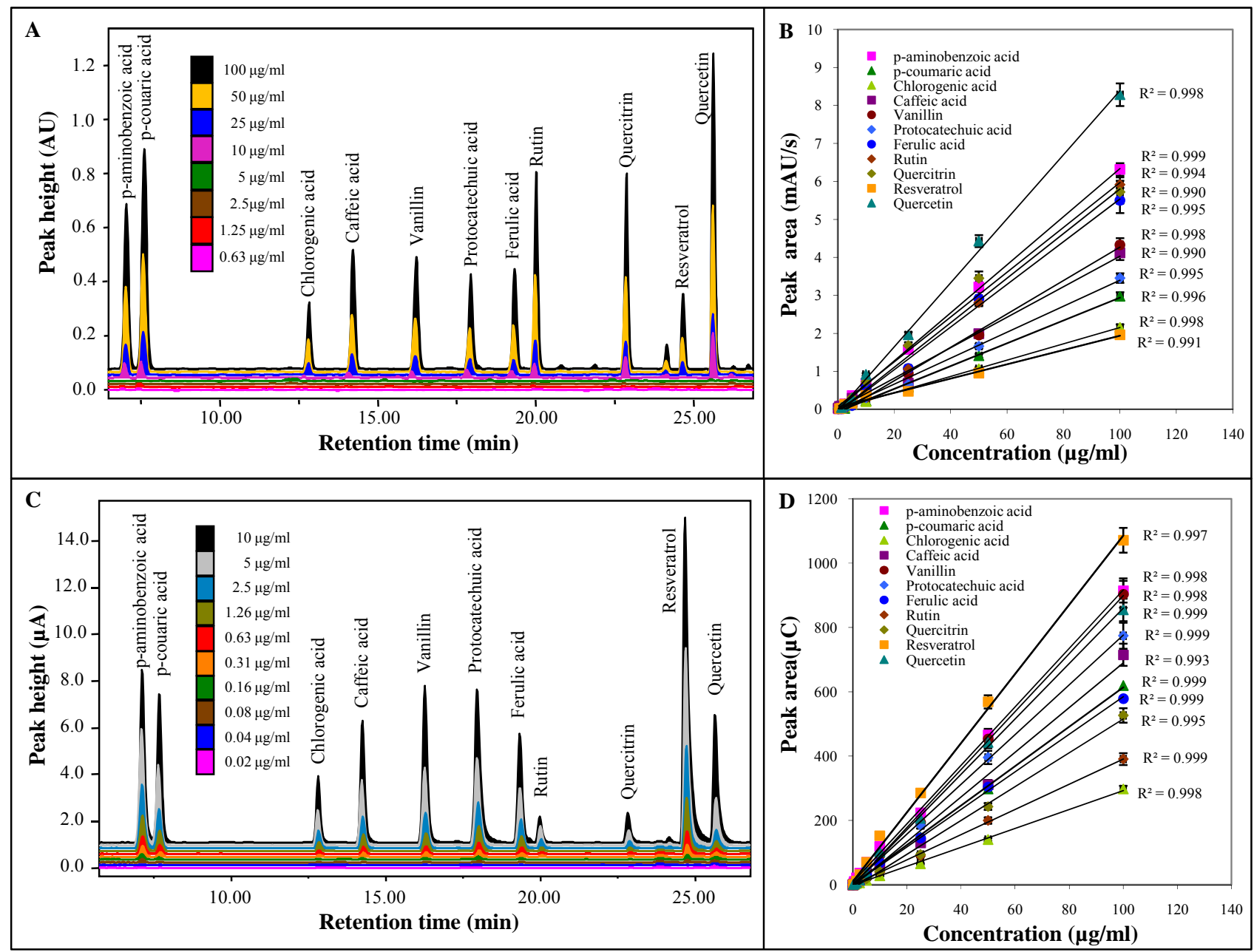

The lowest limits of electrochemical detection were observed in ferulic acid, quercitrin, resveratrol and quercetin. These results indicate that the coulometric detection is under universal potential of $600 \mathrm{mV}$ much suitable and sensitive for polyphenols determination than UV detection under universal wavelength $260 \mathrm{~nm}$. 
Table 1. Analytical parameters of UV detection.

\begin{tabular}{|c|c|c|c|c|c|c|c|c|c|c|c|}
\hline Compounds $^{1}$ & Regresion equation & $\begin{array}{c}\text { Linear dynamic range } \\
(\mu \mathrm{M})\end{array}$ & $\begin{array}{l}\text { Linear dynamic range } \\
\qquad(\mu \mathrm{g} / \mathrm{mL})\end{array}$ & $\mathbf{R}^{2,2}$ & $\begin{array}{l}\mathbf{L O D}^{3} \\
(\mu \mathrm{M})\end{array}$ & $\begin{array}{c}\text { LOD } \\
(\mu \mathrm{g} / \mathrm{mL})\end{array}$ & $\begin{array}{c}\text { LOD (nmol } \\
\text { per injection) }\end{array}$ & $\begin{array}{c}\mathrm{LOQ}^{4} \\
(\mu \mathrm{M})\end{array}$ & $\begin{array}{c}\text { LOQ } \\
(\mu g / m L)\end{array}$ & $\begin{array}{c}\text { LOQ (nmol } \\
\text { per injection) }\end{array}$ & $\begin{array}{r}\mathrm{RSD}^{5} \\
(\%)\end{array}$ \\
\hline p-Aminobenzoic acid & $y=0.0633 x+0.0085$ & $0.918-609.162$ & $0.3125-100$ & 1.000 & 9 & 2 & 0.2 & 31 & 5 & 0.6 & 2.6 \\
\hline$p$-Coumaric acid & $y=0.03 x-0.0663$ & $1.904-729.182$ & $2.5-100$ & 0.997 & 23 & 3 & 0.5 & 77 & 11 & 1.5 & 4.2 \\
\hline Chlorogenic acid & $y=0.0215 x+0.0083$ & $18.229-282.239$ & $0.3125-100$ & 0.999 & 13 & 4 & 0.3 & 42 & 15 & 0.8 & 3.8 \\
\hline Caffeic acid & $y=0.0401 x+0.0176$ & $0.882-555.062$ & $0.039-100$ & 0.991 & 13 & 2 & 0.3 & 44 & 8 & 0.9 & 4.5 \\
\hline Vanillin & $y=0.0439 x-0.1269$ & $0.216-655.824$ & $2.5-100$ & 0.998 & 14 & 2 & 0.3 & 47 & 7 & 0.9 & 4.1 \\
\hline Protocatechuic acid & $\mathrm{y}=0.0341 \mathrm{x}-0.016$ & $16.396-648.845$ & $0.01953-100$ & 0.996 & 18 & 3 & 0.4 & 60 & 9 & 1.2 & 3.6 \\
\hline Ferulic acid & $y=0.0562 x-0.0818$ & $0.127-163.795$ & $0.625-100$ & 0.996 & 3 & 2 & 0.1 & 9 & 6 & 0.2 & 6.0 \\
\hline Rutin & $y=0.0586 x-0.0671$ & $1.024-514.986$ & $0.15625-100$ & 0.995 & 8 & 2 & 0.2 & 28 & 5 & 0.6 & 3.2 \\
\hline Quercitrin & $y=0.059 x+0.0657$ & $0.805-223.025$ & $0.3125-100$ & 0.991 & 4 & 2 & 0.1 & 12 & 5 & 0.2 & 2.5 \\
\hline Resveratrol & $y=0.0188 x+0.0567$ & $0.697-437.828$ & $0.625-100$ & 0.992 & 22 & 5 & 0.4 & 74 & 17 & 1.5 & 3.9 \\
\hline Quercetin & $y=0.0838 x-0.0105$ & $2.736-330.863$ & $0.25-100$ & 0.998 & 4 & 1 & 0.1 & 13 & 4 & 0.3 & 5.2 \\
\hline
\end{tabular}

${ }^{1}$ studied flavonoid; ${ }^{2}$ regression coefficients; ${ }^{3}$ limits of detection of detector $(3 \mathrm{~S} / \mathrm{N}) ;{ }^{4}$ limits of quantification of detector $(10 \mathrm{~S} / \mathrm{N}) ;{ }^{5}$ relative standard deviations

Table 2. Analytical parameters of electrochemical detection.

\begin{tabular}{|c|c|c|c|c|c|c|c|c|c|c|c|}
\hline Compounds $^{1}$ & Regression equation & $\begin{array}{c}\text { Linear dynamic range } \\
(\mu \mathrm{M})\end{array}$ & $\begin{array}{c}\text { Linear dynamic range } \\
(\mu \mathrm{g} / \mathrm{mL})\end{array}$ & $\mathbf{R}^{2,2}$ & $\begin{array}{l}\mathbf{L O D}^{3} \\
(\mathrm{nM})\end{array}$ & $\begin{array}{c}\text { LOD } \\
\text { (ng/mL) }\end{array}$ & $\begin{array}{c}\text { LOD (fmol } \\
\text { per injection) }\end{array}$ & $\begin{array}{l}\mathbf{L O Q}^{4} \\
(\mathrm{nM})\end{array}$ & $\begin{array}{c}\text { LOQ } \\
(\mathrm{ng} / \mathrm{mL})\end{array}$ & $\begin{array}{c}\text { LOQ (fmol } \\
\text { per injection) }\end{array}$ & $\begin{array}{c}\text { RSD }^{5} \\
(\%)\end{array}$ \\
\hline$p$-Aminobenzoic acid & $y=9.093 x+7.7544$ & $11.59-609.16$ & $0.01953-100$ & 0.999 & 64 & 10 & 1.3 & 213 & 35 & 4 & 4.1 \\
\hline$p$-Coumaric acid & $y=6.125 x+1.7966$ & $132.92-729.18$ & $0.01953-100$ & 0.999 & 114 & 16 & 2.3 & 378 & 52 & 8 & 3.3 \\
\hline Chlorogenic acid & $y=2.9465 x-1.5373$ & $2.48-282.23$ & $0.07812-100$ & 0.999 & 91 & 32 & 1.8 & 304 & 108 & 6 & 3.5 \\
\hline Caffeic acid & $y=6.9471 x-4.8188$ & $1.20-555.06$ & $0.07812-100$ & 0.994 & 76 & 14 & 1.5 & 254 & 46 & 5 & 4.8 \\
\hline Vanillin & $y=9.0092 x-1.8005$ & $107.52-655.82$ & $0.0048825-100$ & 0.999 & 69 & 11 & 1.4 & 231 & 35 & 5 & 4.6 \\
\hline Protocatechuic acid & $y=5.8399 x+0.9644$ & $0.82-648.84$ & $0.001220625-100$ & 0.999 & 106 & 16 & 2.1 & 353 & 54 & 7 & 5.2 \\
\hline Ferulic acid & $y=5.8399 x+0.9644$ & $1.67-163.79$ & $0.001220625-100$ & 0.999 & 27 & 16 & 0.5 & 89 & 54 & 2 & 4.4 \\
\hline Rutin & $y=3.9155 x-0.2336$ & $4.41-514.98$ & $0.02441251-100$ & 0.999 & 126 & 24 & 2.5 & 418 & 81 & 8 & 4.7 \\
\hline Quercitrin & $y=5.2613 x-10.4580$ & $1.55-223.02$ & $0.0625-100$ & 0.995 & 40 & 18 & 0.8 & 135 & 60 & 3 & 4.3 \\
\hline Resveratrol & $y=10.759 x+10.4070$ & $11.98-437.82$ & $0.07812-100$ & 0.998 & 39 & 9 & 0.8 & 129 & 30 & 3 & 3.6 \\
\hline Quercetin & $\mathrm{y}=8.6111 \mathrm{x}-0.7735$ & $2.73-330.86$ & $0.15625-100$ & 0.999 & 37 & 11 & 0.7 & 122 & 37 & 2 & 4.1 \\
\hline
\end{tabular}

\footnotetext{
${ }^{1}$ studied flavonoid; ${ }^{2}$ regression coefficients; ${ }^{3}$ limits of detection of detector $(3 \mathrm{~S} / \mathrm{N}) ;{ }^{4}$ limits of quantification of detector $(10 \mathrm{~S} / \mathrm{N}) ;{ }^{5}$ relative standard deviations.
} 


\subsection{Testing of solvents for extraction of phenolics}

It is a common knowledge that the chemical extraction yield is dependent on the type and polarity of solvents, extraction time and temperature, sample-to-solvent ratio as well as on the chemical composition and physical characteristics of the sample. The solubility of phenolics is governed by the chemical nature of the plant sample, as well as the polarity of the solvents used. Plant materials may contain phenolics varying from simple to highly polymerized substances in different quantities. Therefore, there is no universal extraction solvent suitable for extraction of all plant phenolics. Solvents such as 20\% acetone, 60\% methanol and their combination with water in a 20:20:60\% ratio (WAM) was used for the extraction of phenolics from lyophilizates of LE-1075 cultivar. This cultivar was used in our experiments because of a high content of polyphenols in comparison to other cultivars. All samples were spiked with standards to determine the recovery. For spiking low, medium and high concentrations of the polyphenols of interest were used. These were $5 \mu \mathrm{g} / \mathrm{mL}$ for rutin and chlorogenic acid, $0.628 \mu \mathrm{g} / \mathrm{mL}$ for caffeic acid, vanillin, quercetin and $0.078 \mu \mathrm{g} / \mathrm{mL}$ for $p$-aminobenzoic acid, protocatechuic acid, $p$-coumaric acid, ferulic acid, resveratrol and quercitrin. The recovery for the individual substances was calculated from the measured values (Tables 3-5). It is evident that the highest recovery of polyphenols was achieved using WAM solvent (Figure 4A). However, it is obvious that the effectiveness of extraction of individual substances is different for particular solvents because of different chemical structures of the polyphenols. Many authors have considered [87], aqueous methanol as one of the most effective extraction solvents. Our results showed that WAM solution in comparison with other solvents was the most effective for $p$-aminobenzoic acid, chlorgenic acid, caffeic acid, protocatechuic acid, ferulic acid, rutin, resveratrol and qercetin. Other polyphenols such as $p$-coumaric acid and vanillin had the highest recovery using a solvent of $60 \%$ methanol and quercitrin using 20\% acetone. In comparison to other authors, Turkmen reached a much higher recovery of polyphenols using 50\% acetone than with other solvents [88]. Generally, similar results were reached using $60 \%$ methanol and $20 \%$ acetone as a solvent but only in quercitrin analysis, the higher recovery was determined using of $20 \%$ acetone. In Figure 4 results achieved from WAM extraction are shown corresponding with the results of Krygier et al. [89].

Figure 4. (a) Sum of recoveries for three various extraction solvents (b) Sum of recoveries for six various conditions (e.g., maceration $22^{\circ} \mathrm{C}$ as control).

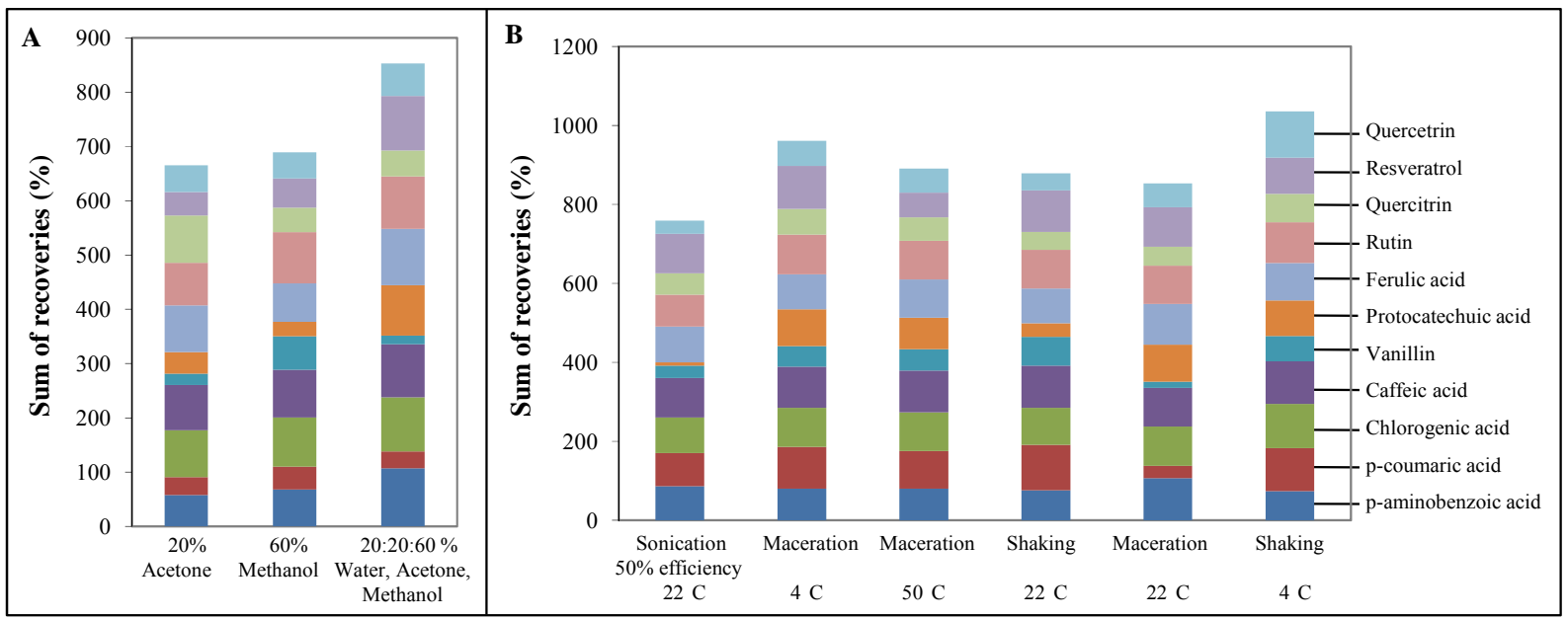


Table 3. Add Recovery of 20\% Acetone.

\begin{tabular}{ccccc}
\hline Compounds & $\begin{array}{c}\text { Homogenate } \\
\mathbf{( n g / m L )}\end{array}$ & $\begin{array}{c}\text { Spiking } \\
\mathbf{( n g} / \mathbf{m L} \mathbf{)}\end{array}$ & $\begin{array}{c}\text { Homogenate }+ \text { spiking } \\
\mathbf{( n g} / \mathbf{m L})\end{array}$ & $\begin{array}{c}\text { Recovery } \\
\mathbf{( \% )}\end{array}$ \\
\hline p-aminobenzoic acid & $56 \pm 4$ & $495 \pm 35$ & $319 \pm 22$ & 58 \\
p-coumaric acid & $45 \pm 5$ & $131 \pm 16$ & $58 \pm 7$ & 33 \\
Chlorogenic acid & $5014 \pm 301$ & $4936 \pm 296$ & $8546 \pm 513$ & 86 \\
Caffeic acid & $128 \pm 11$ & $570 \pm 51$ & $586 \pm 53$ & 84 \\
Vanillin & $356 \pm 29$ & $651 \pm 52$ & $209 \pm 17$ & 21 \\
Protocatechuic acid & $15 \pm 1$ & $119 \pm 12$ & $53 \pm 5$ & 40 \\
Ferulic acid & $40 \pm 6$ & $76 \pm 11$ & $100 \pm 14$ & 86 \\
Rutin & $4890 \pm 342$ & $5555 \pm 389$ & $8205 \pm 574$ & 79 \\
Quercitrin & $0 \pm 0$ & $171 \pm 9$ & $150 \pm 7$ & 87 \\
Resveratrol & $48 \pm 5$ & $1173 \pm 129$ & $528 \pm 58$ & 43 \\
Quercetin & $159 \pm 19$ & $368 \pm 44$ & $259 \pm 31$ & 49 \\
\hline
\end{tabular}

Table 4. Recovery of $60 \%$ Methanol.

\begin{tabular}{ccccc}
\hline Compounds & $\begin{array}{c}\text { Homogenate } \\
(\mathbf{n g} / \mathbf{m L})\end{array}$ & $\begin{array}{c}\text { Spiking } \\
(\mathbf{n g} / \mathbf{m L})\end{array}$ & $\begin{array}{c}\text { Homogenate + spiking } \\
\mathbf{( n g} / \mathbf{m L})\end{array}$ & $\begin{array}{c}\text { Recovery } \\
\mathbf{( \% )}\end{array}$ \\
\hline p-aminobenzoic acid & $52 \pm 4$ & $411 \pm 29$ & $315 \pm 22$ & 68 \\
p-coumaric acid & $32 \pm 4$ & $122 \pm 15$ & $64 \pm 8$ & 42 \\
Chlorogenic acid & $3762 \pm 226$ & $4936 \pm 296$ & $7880 \pm 473$ & 91 \\
Caffeic acid & $41 \pm 4$ & $559 \pm 50$ & $527 \pm 47$ & 88 \\
Vanillin & $32 \pm 3$ & $654 \pm 52$ & $427 \pm 34$ & 62 \\
Protocatechuic acid & $60 \pm 6$ & $95 \pm 9$ & $40 \pm 4$ & 26 \\
Ferulic acid & $50 \pm 7$ & $76 \pm 11$ & $90 \pm 13$ & 71 \\
Rutin & $8320 \pm 582$ & $6898 \pm 483$ & $14348 \pm 1004$ & 94 \\
Quercitrin & $5 \pm 0$ & $238 \pm 12$ & $109 \pm 5$ & 45 \\
Resveratrol & $73 \pm 8$ & $1079 \pm 119$ & $622 \pm 68$ & 54 \\
Quercetin & $162 \pm 19$ & $268 \pm 32$ & $207 \pm 25$ & 48 \\
\hline
\end{tabular}

Table 5. Recovery of 20:20:60\% - Water, Acetone, Methanol.

\begin{tabular}{ccccc}
\hline Compounds & $\begin{array}{c}\text { Homogenate } \\
\mathbf{( n g / m L )}\end{array}$ & $\begin{array}{c}\text { Spiking } \\
\mathbf{( n g / m L )}\end{array}$ & $\begin{array}{c}\text { Homogenate }+ \text { spiking } \\
\text { (ng/mL) }\end{array}$ & $\begin{array}{c}\text { Recovery } \\
\mathbf{( \% )}\end{array}$ \\
\hline p-aminobenzoic acid & $11 \pm 1$ & $317 \pm 22$ & $350 \pm 25$ & 107 \\
p-coumaric acid & $47 \pm 6$ & $88 \pm 11$ & $42 \pm 5$ & 31 \\
Chlorogenic acid & $12040 \pm 722$ & $4936 \pm 296$ & $16964 \pm 1018$ & 100 \\
Caffeic acid & $282 \pm 25$ & $526 \pm 47$ & $790 \pm 71$ & 98 \\
Vanillin & $817 \pm 65$ & $643 \pm 51$ & $235 \pm 19$ & 16 \\
Protocatechuic acid & $15 \pm 1$ & $41 \pm 4$ & $52 \pm 5$ & 93 \\
Ferulic acid & $115 \pm 16$ & $76 \pm 11$ & $198 \pm 28$ & 104 \\
Rutin & $7388 \pm 517$ & $4924 \pm 345$ & $11921 \pm 834$ & 97 \\
Quercitrin & $0 \pm 0$ & $196 \pm 10$ & $93 \pm 5$ & 48 \\
Resveratrol & $11 \pm 1$ & $988 \pm 109$ & $1006 \pm 111$ & 101 \\
Quercetin & $129 \pm 15$ & $250 \pm 30$ & $227 \pm 27$ & 60 \\
\hline
\end{tabular}

\subsection{Testing of sonication and vortexing on extraction of phenolics}

Various extraction operations can influence the extraction yield. In this study, we tested the influence of sonication, vortexing and non-physico-chemical operations on extraction efficiency. To determine the effect of physical extraction methods, the above optimized MAW extraction solution was used. Lyophilized sample (LE-1075) was crushed in a mortar with the extraction solution for 
2 min at $4{ }^{\circ} \mathrm{C}$ to avoid evaporation of reagents. Further, the following physical methods of extraction were tested: sonication at $50 \%$ efficiency and room temperature $22{ }^{\circ} \mathrm{C}$, maceration at $4{ }^{\circ} \mathrm{C}$, maceration at $50{ }^{\circ} \mathrm{C}$, vortexing at $22{ }^{\circ} \mathrm{C}$, maceration at $22{ }^{\circ} \mathrm{C}$ and vortexing at $4{ }^{\circ} \mathrm{C}$. All samples were spiked with their standards to determine the recovery. For spiking low, medium and high concentrations of the polyphenols of interest were used. These were $5 \mu \mathrm{g} / \mathrm{mL}$ for rutin and chlorogenic acid, $0.628 \mu \mathrm{g} / \mathrm{mL}$ for caffeic acid, vanillin, quercetin and $0.078 \mu \mathrm{g} / \mathrm{mL}$ for $p$-aminobenzoic acid, protocatechuic acid, $p$ coumaric acid, ferulic acid, resveratrol and quercitrin. The recovery of the individual substances was calculated from the measured values (Tables 6-10). Physical methods had a greater influence on the yield of total polyphenolic compounds than the individual compounds (Figure 4B). Many authors have extracted polyphenolic substances at room and higher temperatures [90]. Our results show that for the apricot matrix we achieved a good yield of determined compounds by using maceration at $4{ }^{\circ} \mathrm{C}$ and $50{ }^{\circ} \mathrm{C}$. All physical procedures carried out at room temperature had lower yield compared to higher temperatures due to faster diffusion. Even lower yields than the maceration at room temperature were achieved by sonication. Generally, sonication is efficient and rapid extraction method [91,92]. Using ultrasonic waves we observed relatively low yield for protocatechuic acid, vanillin and quercitrin (Figure 4B). This could be caused by partial degradation of the monitored compounds. Based on the results obtained it can be concluded that the highest yield was reached by vortexing at $4{ }^{\circ} \mathrm{C}$. Under these conditions, the highest recoveries were obtained for all studied polyphenols except for $p$ aminobenzoic acid, which recovery was highest using maceration at $4{ }^{\circ} \mathrm{C}$.

Table 6. Sonication at $22{ }^{\circ} \mathrm{C}, 50 \%$ efficiency.

\begin{tabular}{ccccc}
\hline Compounds & $\begin{array}{c}\text { Homogenate } \\
(\mathbf{n g} / \mathbf{m L})\end{array}$ & $\begin{array}{c}\text { Spiking } \\
\mathbf{( n g} / \mathbf{m L})\end{array}$ & $\begin{array}{c}\text { Homogenate + spiking } \\
\mathbf{( n g} / \mathbf{m L} \mathbf{)}\end{array}$ & $\begin{array}{c}\text { Recovery } \\
\mathbf{( \% )}\end{array}$ \\
\hline p-aminobenzoic acid & $21 \pm 1$ & $325 \pm 23$ & $300 \pm 21$ & 87 \\
p-coumaric acid & $18 \pm 2$ & $137 \pm 16$ & $129 \pm 15$ & 83 \\
Chlorogenic acid & $11023 \pm 661$ & $4936 \pm 296$ & $14486 \pm 869$ & 91 \\
Caffeic acid & $281 \pm 25$ & $498 \pm 45$ & $773 \pm 70$ & 99 \\
Vanillin & $604 \pm 48$ & $565 \pm 45$ & $364 \pm 29$ & 31 \\
Protocatechuic acid & $58 \pm 6$ & $55 \pm 5$ & $10 \pm 1$ & 9 \\
Ferulic acid & $90 \pm 13$ & $76 \pm 11$ & $150 \pm 21$ & 90 \\
Rutin & $15605 \pm 1092$ & $6228 \pm 436$ & $17768 \pm 1244$ & 81 \\
Quercitrin & $1 \pm 0$ & $179 \pm 9$ & $97 \pm 5$ & 54 \\
Resveratrol & $2 \pm 0$ & $965 \pm 106$ & $963 \pm 106$ & 100 \\
Quercetin & $135 \pm 16$ & $224 \pm 27$ & $120 \pm 14$ & 33 \\
\hline
\end{tabular}

Table 7. Maceration $4{ }^{\circ} \mathrm{C}$.

\begin{tabular}{ccccc}
\hline Compounds & $\begin{array}{c}\text { Homogenate } \\
(\mathbf{n g} / \mathbf{m L})\end{array}$ & $\begin{array}{c}\text { Spiking } \\
\mathbf{( n g / m L})\end{array}$ & $\begin{array}{c}\text { Homogenate + spiking } \\
\mathbf{( n g} / \mathbf{m L})\end{array}$ & $\begin{array}{c}\text { Recovery } \\
\mathbf{( \% )}\end{array}$ \\
\hline p-aminobenzoic acid & $11 \pm 1$ & $262 \pm 18$ & $218 \pm 15$ & 80 \\
p-coumaric acid & $10 \pm 1$ & $121 \pm 14$ & $139 \pm 17$ & 106 \\
Chlorogenic acid & $12666 \pm 760$ & $4936 \pm 296$ & $17420 \pm 1045$ & 99 \\
Caffeic acid & $276 \pm 25$ & $415 \pm 37$ & $719 \pm 65$ & 104 \\
Vanillin & $190 \pm 15$ & $472 \pm 38$ & $348 \pm 28$ & 53 \\
Protocatechuic acid & $10 \pm 1$ & $47 \pm 5$ & $54 \pm 5$ & 93 \\
Ferulic acid & $103 \pm 14$ & $76 \pm 11$ & $158 \pm 22$ & 88 \\
Rutin & $15710 \pm 1100$ & $5354 \pm 375$ & $21093 \pm 1477$ & 100 \\
Quercitrin & $2 \pm 0$ & $142 \pm 7$ & $95 \pm 5$ & 66 \\
Resveratrol & $9 \pm 1$ & $803 \pm 88$ & $884 \pm 97$ & 109 \\
Quercetin & $101 \pm 12$ & $200 \pm 24$ & $190 \pm 23$ & 63 \\
\hline
\end{tabular}


Table 8. Maceration $50{ }^{\circ} \mathrm{C}$.

\begin{tabular}{ccccc}
\hline Compounds & $\begin{array}{c}\text { Homogenate } \\
\text { (ng/mL) }\end{array}$ & $\begin{array}{c}\text { Spiking } \\
(\mathbf{n g} / \mathbf{m L})\end{array}$ & $\begin{array}{c}\text { Homogenate + spiking } \\
(\mathbf{n g} / \mathbf{m L})\end{array}$ & $\begin{array}{c}\text { Recovery } \\
(\mathbf{\%})\end{array}$ \\
\hline p-aminobenzoic acid & $35 \pm 2$ & $262 \pm 18$ & $238 \pm 17$ & 80 \\
p-coumaric acid & $22 \pm 3$ & $113 \pm 14$ & $129 \pm 16$ & 96 \\
Chlorogenic acid & $15357 \pm 921$ & $4936 \pm 296$ & $19812 \pm 1189$ & 98 \\
Caffeic acid & $328 \pm 30$ & $408 \pm 37$ & $775 \pm 70$ & 105 \\
Vanillin & $257 \pm 21$ & $462 \pm 37$ & $393 \pm 31$ & 55 \\
Protocatechuic acid & $17 \pm 2$ & $48 \pm 5$ & $52 \pm 5$ & 80 \\
Ferulic acid & $122 \pm 17$ & $76 \pm 11$ & $192 \pm 27$ & 97 \\
Rutin & $19300 \pm 1351$ & $5464 \pm 382$ & $24366 \pm 1706$ & 98 \\
Quercitrin & $0 \pm 0$ & $141 \pm 7$ & $83 \pm 4$ & 59 \\
Resveratrol & $39 \pm 4$ & $805 \pm 89$ & $533 \pm 59$ & 63 \\
Quercetin & $122 \pm 15$ & $195 \pm 23$ & $192 \pm 23$ & 61 \\
\hline
\end{tabular}

Table 9. Shaking $22{ }^{\circ} \mathrm{C}$.

\begin{tabular}{ccccc}
\hline Compounds & $\begin{array}{c}\text { Homogenate } \\
\text { (ng/mL) }\end{array}$ & $\begin{array}{c}\text { Spiking } \\
\text { (ng/mL) }\end{array}$ & $\begin{array}{c}\text { Homogenate }+ \text { spiking } \\
\text { (ng/mL) }\end{array}$ & $\begin{array}{c}\text { Recovery } \\
\text { (\%) }\end{array}$ \\
\hline p-aminobenzoic acid & $19 \pm 1$ & $290 \pm 20$ & $290 \pm 20$ & 76 \\
p-coumaric acid & $10 \pm 1$ & $77 \pm 9$ & $77 \pm 9$ & 115 \\
Chlorogenic acid & $11056 \pm 663$ & $4936 \pm 296$ & $4936 \pm 296$ & 94 \\
Caffeic acid & $237 \pm 21$ & $442 \pm 40$ & $442 \pm 40$ & 107 \\
Vanillin & $886 \pm 71$ & $477 \pm 38$ & $477 \pm 38$ & 73 \\
Protocatechuic acid & $25 \pm 2$ & $142 \pm 14$ & $142 \pm 14$ & 34 \\
Ferulic acid & $100 \pm 14$ & $76 \pm 11$ & $76 \pm 11$ & 88 \\
Rutin & $14316 \pm 1002$ & $4993 \pm 349$ & $4993 \pm 349$ & 98 \\
Quercitrin & $1 \pm 0$ & $156 \pm 8$ & $156 \pm 8$ & 45 \\
Resveratrol & $41 \pm 5$ & $869 \pm 96$ & $869 \pm 96$ & 105 \\
Quercetin & $78 \pm 9$ & $146 \pm 18$ & $146 \pm 18$ & 43 \\
\hline
\end{tabular}

Table 10. Shaking $4{ }^{\circ} \mathrm{C}$.

\begin{tabular}{ccccc}
\hline Compounds & $\begin{array}{c}\text { Homogenate } \\
(\mathbf{n g} / \mathbf{m L})\end{array}$ & $\begin{array}{c}\text { Spiking } \\
\mathbf{( n g} / \mathbf{m L})\end{array}$ & $\begin{array}{c}\text { Homogenate }+ \text { spiking } \\
\text { (ng/mL) }\end{array}$ & $\begin{array}{c}\text { Recovery } \\
\text { (\%) }\end{array}$ \\
\hline p-aminobenzoic acid & $155 \pm 11$ & $2589 \pm 181$ & $2033 \pm 142$ & 74 \\
p-coumaric acid & $14 \pm 2$ & $943 \pm 113$ & $1039 \pm 125$ & 109 \\
Chlorogenic acid & $13397 \pm 804$ & $2613 \pm 157$ & $17969 \pm 1078$ & 112 \\
Caffeic acid & $338 \pm 30$ & $629 \pm 57$ & $1043 \pm 94$ & 108 \\
Vanillin & $8 \pm 1$ & $613 \pm 49$ & $396 \pm 32$ & 64 \\
Protocatechuic acid & $89 \pm 9$ & $1655 \pm 166$ & $1572 \pm 157$ & 90 \\
Ferulic acid & $104 \pm 15$ & $619 \pm 87$ & $687 \pm 96$ & 95 \\
Rutin & $10646 \pm 745$ & $3256 \pm 228$ & $14276 \pm 999$ & 103 \\
Quercitrin & $82 \pm 4$ & $253 \pm 13$ & $241 \pm 12$ & 72 \\
Resveratrol & $83 \pm 9$ & $191 \pm 21$ & $254 \pm 28$ & 93 \\
Quercetin & $164 \pm 20$ & $406 \pm 49$ & $666 \pm 80$ & 117 \\
\hline
\end{tabular}

\subsection{Real samples of apricots}

Further, our optimized method was used for preparation and analysis of real samples of apricots. Cultivars Mamaria, Mold and LE-1075 were prepared using solvent mixture of 20:20:60\% WAM and vortexing at $4{ }^{\circ} \mathrm{C}$, as the optimal conditions with the highest yield. The content of each polyphenol in 
each cultivar varied (Figure 5, Table 11). Chlorgenic acid and rutin were the major phenolic compounds in apricot fruits. Similar results were determined also by Bors et al. [93]. Average content of chlorgenic acid was $2302 \mathrm{mg} / 100 \mathrm{~g}$ in cultivar LE-1075, $546 \mathrm{mg} / 100 \mathrm{~g}$ in cultivar Mamaria and $128.59 \mathrm{mg} / 100 \mathrm{~g}$ in cultivar Mold. According to Dragovic-Uzelac et al. the quantity of chlorgenic acid in apricot fruits varied depending on maturity stages but no correlation between the degree of maturity and its amount was observed [94]. Quercitrin $(227 \mathrm{mg} / 100 \mathrm{~g}$ of apricot) and vanilin $(261.89 \mathrm{mg} / 100 \mathrm{~g}$ of apricot) were present in remarkable amounts in cultivar LE-1075, but in other two cultivars they were negligible $(0.79 \mathrm{mg} / 100 \mathrm{~g}$ in Mold and $1.72 \mathrm{mg} / 100 \mathrm{~g}$ in Mamaria). The other polyphenols identified in apricot fruits (protocatechuic acid, $p$-coumaric, $p$-aminobenzoic acid and ferulic acid) were of low content compared to the previous ones. Generally, the cultivar LE-1075 reaches the highest values in polyphenols content in contrary to Mold, which was relatively poor from the point of the content of phenolics.

Figure 5. (a) Real chromatogram of Mamaria cultivar overlaid with standard mixture of analyzed polyphenols. (b) Real chromatogram of LE-1075 cultivar overlaid with standard mixture of analyzed polyphenols. (c) Real chromatogram of Mold cultivar overlaid with standard mixture of analyzed polyphenols.

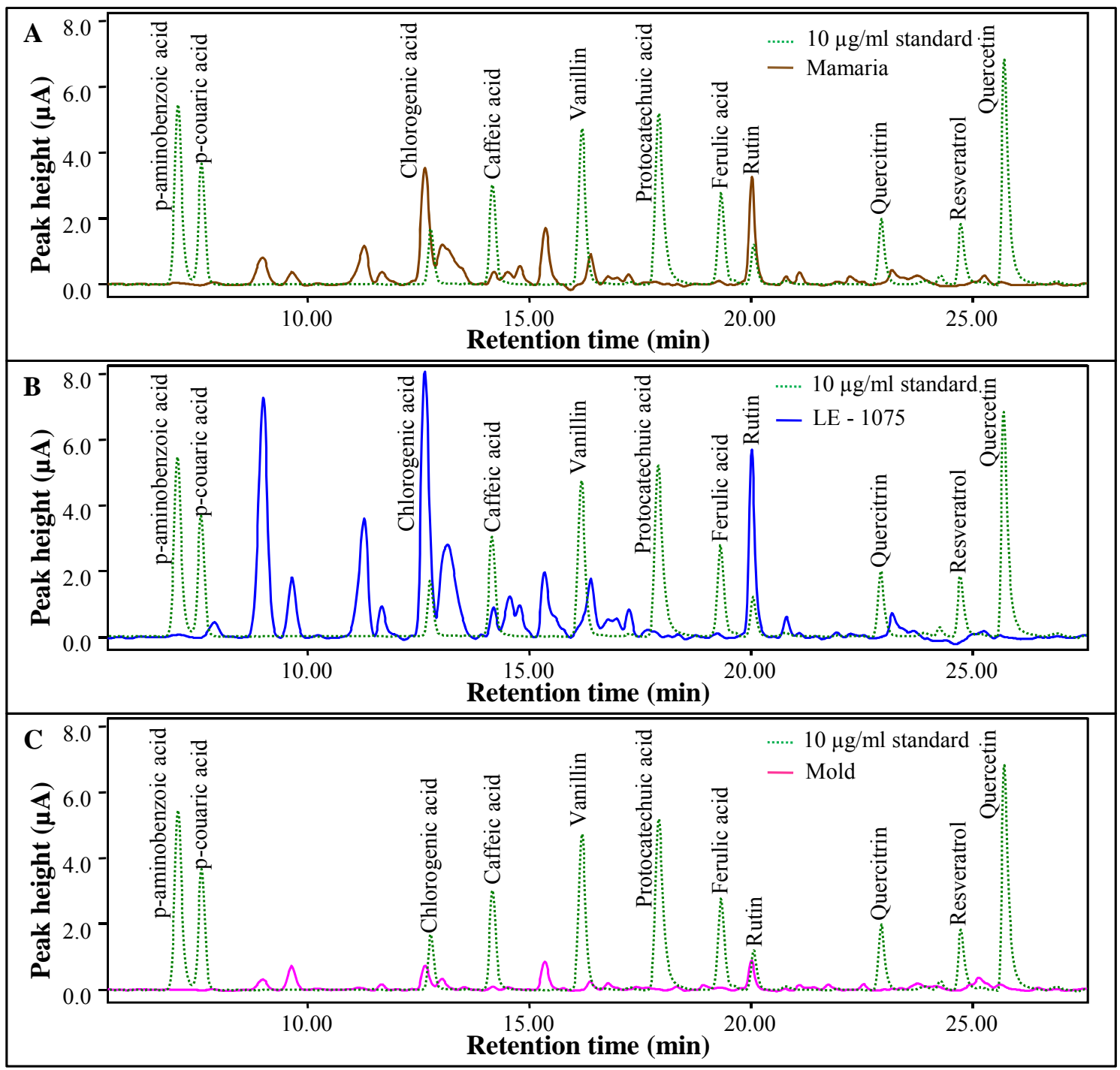


Table 11. Analytical results.

\begin{tabular}{cccc}
\hline Compounds & Mold $(\mathbf{n g} / \mathbf{m L})$ & LE-1075 (ng/mL) & Mamaria (ng/mL) \\
\hline p-aminobenzoic acid & $100 \pm 7$ & $501 \pm 35$ & $01,427 \pm 99$ \\
p-coumaric acid & $1,722 \pm 155$ & $20,49 \pm 1,844$ & $129 \pm 11$ \\
Chlorogenic acid & $64,294 \pm 8,358$ & $1,150,979 \pm 149,627$ & $273,019 \pm 35,492$ \\
Caffeic acid & $2,937 \pm 176$ & $16,663 \pm 999$ & $7,042 \pm 422$ \\
Vanillin & $15,664 \pm 2,193$ & $130,946 \pm 18,332$ & $805 \pm 112$ \\
Protocatechuic acid & $1,117 \pm 122$ & $959 \pm 105$ & $2,040 \pm 224$ \\
Ferulic acid & $3,267 \pm 294$ & $8,460 \pm 761$ & $6,369 \pm 573$ \\
Rutin & $60,457 \pm 3,022$ & $373,734 \pm 18,686$ & $346,355 \pm 17,317$ \\
Quercitrin & $396 \pm 39$ & $113,500 \pm 11,350$ & $861 \pm 86$ \\
Resveratrol & $96 \pm 12$ & $2,256 \pm 293$ & $136 \pm 17$ \\
Quercetin & $3,611 \pm 541$ & $3,241 \pm 486$ & $2,772 \pm 415$ \\
\hline
\end{tabular}

\section{Experimental}

\subsection{Chemicals and pH measurements}

The stock standard solutions of polyphenols $(1 \mathrm{mM})$ was prepared with acetonitrile (Sigma-Aldrich, USA) and stored in the dark at $-20{ }^{\circ} \mathrm{C}$. Working standard solutions were prepared daily by dilution of the stock solutions with acetonitrile. All chemical used were of ACS purity (chemicals meeting the specifications of the American Chemical Society). The $\mathrm{pH}$ value was measured using inoLab Level 3 with terminal Level 3 (Wissenschaftlich-Technische Werkstätten-WTW, Weilheim, Germany), controlled by the personal computer program (MultiLab Pilot; WTW). The pH-electrode (SenTix-H, $\mathrm{pH} \quad 0-14 / 3 \mathrm{M} \mathrm{KCl}$ ) was calibrated by set of buffers (WTW). Deionised water underwent demineralization by reverse osmosis using the instruments Aqua Osmotic 02 (Aqua Osmotic, Tisnov, Czech Republic) and then it was subsequently purified using Millipore RG (Millipore Corp., USA, 18 $\mathrm{M} \Omega$ ) - MiliQ water.

\subsection{Biological material}

Apricots crossbreed (Prunus armeniaca L.) "Mold", "Mamaria", "LE-1075" were used in our experiments. Plants were planted in Czech Republic, in area of Lednice municipality, climatic region T4. Fruits were harvested at consumption maturity $\left(20^{\text {th }}\right.$ of July 2010). Weight of fruits on trees was $30 \mathrm{~kg}$.

\subsection{Sample preparation}

Frozen fruits were thawed at laboratory temperature and subsequently a sample of each cultivar ( $5 \mathrm{~g}$ ) including flesh and peel was taken. Flesh and peel were homogenized in a mortar. The obtained homogenate was transferred into a Petri dish where it was spread for lyophilization (Christ Alpha 1-2) for 24 hours in $1^{-10} \mathrm{mBar}$ and $-50^{\circ} \mathrm{C}$. Subsequently, the lyophilizates were frozen with liquid nitrogen and spread in a mortar. A sample of lyophilzates (weight of $25 \mathrm{mg}$ ) spread for 2 minutes in the mortar with solvent $(0.5 \mathrm{~mL})$ at $4{ }^{\circ} \mathrm{C}$ was used for extraction. The low temperature was to prevent solvent evaporation. The samples were centrifuged (Eppendorf centrifuge $5417 \mathrm{R}$ ) at $25,000 \mathrm{~g}, 4{ }^{\circ} \mathrm{C}$ for 
30 min after the different extraction methods and subsequently, supernatant was removed and directly analyzed by HPLC.

\subsection{HPLC measurements}

The instrument for HPLC-UV-ED analysis consisted of a solvent delivery pump operating in range of 0.001-9.999 $\mathrm{mL} \cdot \mathrm{min}^{-1}$ (Model 582 ESA Inc., Chelmsford, MA, USA), chromatographic column Phenomenex Gemini $\mathrm{C}_{18}(150 \times 4.6 ; 3 \mu \mathrm{m}$ particles, Phenomenex, USA), UV-VIS detector (Model 528, ESA, USA) and twelve-channel CoulArray electrochemical detector (Model 5600A, ESA, USA). Detector consists of three flow analytical chambers (Model 6210, ESA, USA). Each chamber contains four analytical cells. One analytical cell contains two referent (hydrogen-palladium), and two counters and one porous graphite working electrode. Electrochemical detector is situated in control module which is thermostated. The sample $(20 \mu \mathrm{L})$ was injected using an autosampler (Model 542, ESA, USA). The data obtained were treated by a Coularray data station (ESA, USA). The experiments were carried out at room temperature. Mobile phase consists of A: citric acid (75 mM) a B: ammonium acetate $(25 \mathrm{mM})$. Flow rate was $1 \mathrm{~mL} \cdot \mathrm{min}^{-1}$. Chromatographic column was thermostated to $35{ }^{\circ} \mathrm{C}$. Compounds were eluted by following linear increasing gradient: $0 \rightarrow 1 \mathrm{~min}(5 \% \mathrm{~B}), 1 \rightarrow 4 \mathrm{~min}(6 \% \mathrm{~B})$, $4 \rightarrow 20 \min (25 \%$ B), $20 \rightarrow 30 \min (100 \%$ B), 30 $\rightarrow 36 \min (100 \%$ B), 36 $\rightarrow 38 \min (5 \%$ B), $38 \rightarrow 45 \min$ $(5 \% \mathrm{~B})$. Detection on UV detector was carried out at $260 \mathrm{~nm}$ and detection on ED detector was carried out at $600 \mathrm{mV}$. Time of one analysis was 45 minutes.

\subsection{Estimation of detection limit}

The detection limits (3 signal/noise, $\mathrm{S} / \mathrm{N}$ ) were calculated according to Long and Winefordner [95], whereas $\mathrm{N}$ was expressed as standard deviation of noise determined in the signal domain unless stated otherwise.

\section{Conclusions}

Plant materials may contain phenolics varying from simple to highly polymerized substances in different quantities. Therefore, there is no universal method for their determination. In this work we focused on identifying a suitable method for extraction and determination of polyphenols from apricot samples. We determined protocatechuic acid, 4-aminobenzoic acid, chlorogenic acid, caffeic acid, vanillin, $p$-coumaric acid, rutin, ferulic acid, quercetin, resveratrol, quercitrin from apricot using HPLC with electrochemical and UV detector. The developed method was used for the determination of limits of detection and limits of quantification for apricot samples. Varying amounts of the chosen polyphenols was observed in the apricot cultivars Mamaria, Mold and LE-1075. The major phenolic compounds were chlorgenic acid and rutin.

\section{Acknowledgements}

Financial support from the grants NAZV QI91A032, REMEDTECH GA CR 522/07/0692 is highly acknowledged. 


\section{References}

1. Bruneton, J. Pharmacognosy, Phytochemistry, Medicinal Plants, 2nd ed.; Lavoisier: Paris, France, 1999.

2. Cartea, M.E.; Francisco, M.; Soengas, P.; Velasco, P. Phenolic Compounds in Brassica Vegetables. Molecules 2010, 16, 251-280.

3. Ferretti, G.; Bacchetti, T.; Belleggia, A.; Neri, D. Cherry Antioxidants: From Farm to Table. Molecules 2010, 15, 6993-7005.

4. Sochor, J.; Zitka, O.; Skutkova, H.; Pavlik, D.; Babula, P.; Krska, B.; Horna, A.; Adam, V.; Provaznik, I.; Kizek, R. Content of Phenolic Compounds and Antioxidant Capacity in Fruits of Apricot Genotypes. Molecules 2010, 15, 6285-6305.

5. Sisa, M.; Bonnet, S.L.; Ferreira, D.; Van der Westhuizen, J.H. Photochemistry of Flavonoids. Molecules 2010, 15, 5196-5245.

6. Ghasemzadeh, A.; Jaafar, H.Z.E.; Rahmat, A. Elevated Carbon Dioxide Increases Contents of Flavonoids and Phenolic Compounds, and Antioxidant Activities in Malaysian Young Ginger (Zingiber officinale Roscoe.) Varieties. Molecules 2010, 15, 7907-7922.

7. Kelsey, N.A.; Wilkins, H.M.; Linseman, D.A. Nutraceutical Antioxidants as Novel Neuroprotective Agents. Molecules 2010, 15, 7792-7814.

8. Rechner, A.R.; Wagner, E.; Van Buren, L.; Van de Put, F.; Wiseman, S.; Rice-Evans, C.A. Black tea represents a major source of dietary phenolics among regular tea drinkers. Free Radic. Res. 2002, 36, 1127-1135.

9. Gonzalez-Gallego, J.; Garcia-Mediavilla, M.V.; Sanchez-Campos, S.; Tunon, M.J. Fruit polyphenols, immunity and inflammation. Br. J. Nutr. 2010, 104, S15-S27.

10. Galleano, M.; Pechanova, O.; Fraga, C.G. Hypertension, Nitric Oxide, Oxidants, and Dietary Plant Polyphenols. Curr. Pharm. Biotechnol. 2010, 11, 837-848.

11. Fang, Z.X.; Bhandari, B. Encapsulation of polyphenols - a review. Trends Food Sci. Technol. 2010, 21, 510-523.

12. Michalowicz, J.; Duda, W.; Pol, J. Environ. Stud. Pol. J. Environ. Stud. 2007, 16, 347-362.

13. Chen, H.L.; Yao, J.; Wang, F.; Zhou, Y.; Chen, K.; Zhuang, R.S.; Choi, M.M.F.; Zaray, G. Toxicity of three phenolic compounds and their mixtures on the gram-positive bacteria Bacillus subtilis in the aquatic environment. Sci. Total Environ. 2010, 408, 1043-1049.

14. Shadnia, H.; Wright, J.S. Understanding the toxicity of phenols: Using quantitative structureactivity relationship and enthalpy changes to discriminate between possible mechanisms. Chem. Res. Toxicol. 2008, 21, 1197-1204.

15. Lepoittevin, J.P.; Benezra, C. Allergic contact-dermatitis caused by naturally-occurring quinones. Pharm. Weekblad-Sci. Ed. 1991, 13, 119-122.

16. Saito, S.; Kawabata, J. Effects of electron-withdrawing substituents on DPPH radical scavenging reactions of protocatechuic acid and its analogues in alcoholic solvents. Tetrahedron 2005, 61, 8101-8108.

17. Hatzipanayioti, D.; Karaliota, A.; Kamariotaki, M.; Aletras, V.; Petropouleas, P. Theoretical and spectroscopic investigation of the oxidation and degradation of protocatechuic acid. Chem. Phys. 2006, 325, 341-350. 
18. Kampa, M.; Alexaki, V.I.; Notas, G.; Nifli, A.P.; Nistikaki, A.; Hatzoglou, A.; Bakogeorgou, E.; Kouimtzoglou, E.; Blekas, G.; Boskou, D.; Gravanis, A.; Castanas, E. Antiproliferative and apoptotic effects of selective phenolic acids on T47D human breast cancer cells: potential mechanisms of action. Breast Cancer Res. 2004, 6, R63-R74.

19. Ueda, J.I.; Saito, N.; Shimazu, Y.; Ozawa, T. A comparison of scavenging abilities of antioxidants against hydroxyl radicals. Arch. Biochem. Biophys. 1996, 333, 377-384.

20. An, L.J.; Guan, S.; Shi, G.F.; Bao, Y.M.; Duan, Y.L.; Jiang, B. Protocatechuic acid from Alpinia oxyphylla against MPP+-induced neurotoxicity in PC12 cells. Food Chem. Toxicol. 2006, 44, 436-443.

21. Akberova, S.I. New biological properties of p-aminobenzoic acid. Biol. Bull. 2002, 29, 390-393.

22. Shuang, S.M.; Yang, Y.; Pan, J.H. Study on molecular recognition of para-aminobenzoic acid species by alpha-, beta- and hydroxypropyl-beta-cyclodextrin. Anal. Chim. Acta 2002, 458, 305-310.

23. Schmidt, T.C.; Petersmann, M.; Kaminski, L.; vonLow, E.; Stork, G. Analysis of aminobenzoic acids in waste water from a former ammunition plant with HPLC and combined diode array and fluorescence detection. Fres. J. Anal. Chem. 1997, 357, 121-126.

24. Clifford, M.N. Chlorogenic acids and other cinnamates - nature, occurrence and dietary burden. $J$. Sci. Food Agric. 1999, 79, 362-372.

25. Boerjan, W.; Ralph, J.; Baucher, M. Lignin biosynthesis. Annu. Rev. Plant Biol. 2003, 54, 519-546.

26. Kono, Y.; Kashine, S.; Yoneyama, T.; Sakamoto, Y.; Matsui, Y.; Shibata, H. Iron chelation by chlorogenic acid as a natural antioxidant. Biosci. Biotechnol. Biochem. 1998, 62, 22-27.

27. Halliwell, B.; Gutteridge, J.M.C. Role of free-radicals and catalytic metal-ions in human-disease an overview. Methods Enzymol. 1990, 186, 1-85.

28. Mori, H.; Tanaka, T.; Shima, H.; Asu, T.K.; Takahashi, M. Inhibitory effect of chlorogenic acid on methylazoxymethanol acetate-induced carcinogenesis in large-intestine and liver of hamsters. Cancer Lett. 1986, 30, 49-54.

29. Tsuchiya, T.; Suzuki, O.; Igarashi, K. Protective effects of chlorogenic acid on paraquat-induced oxidative stress in rats. Biosci. Biotechnol. Biochem. 1996, 60, 765-768.

30. Zhao, Z.H.; Moghadasian, M.H. Bioavailability of hydroxycinnamates: a brief review of in vivo and in vitro studies. Phytochem. Rev. 2010, 9, 133-145.

31. Maurya, D.K.; Devasagayam, T.P.A. Antioxidant and prooxidant nature of hydroxycinnamic acid derivatives ferulic and caffeic acids. Food Chem. Toxicol. 2010, 48, 3369-3373.

32. Kono, Y.; Shibata, H.; Kodama, Y.; Sawa, Y. The suppression of the N-nitrosating reaction by chlorogenic acid. Biochem. J. 1995, 312, 947-953.

33. Kasai, H.; Fukada, S.; Yamaizumi, Z.; Sugie, S.; Mori, H. Action of chlorogenic acid in vegetables and fruits as an inhibitor of 8-hydroxydeoxyguanosine formation in vitro and in a rat carcinogenesis model. Food Chem. Toxicol. 2000, 38, 467-471.

34. Shibata, H.; Sakamoto, Y.; Oka, M.; Kono, Y. Natural antioxidant, chlorogenic acid, protects against DNA breakage caused by monochloramine. Biosci. Biotechnol. Biochem. 1999, 63, 1295-1297. 
35. Akagi, K.; Hirose, M.; Hoshiya, T.; Mizoguchi, Y.; Ito, N.; Shirai, T. Modulating effects of ellagic acid, vanillin and quercetin in a rat medium-term multiorgan carcinogenesis model. Cancer Lett. 1995, 94, 113-121.

36. Kappachery, S.; Paul, D.; Yoon, J.; Kweon, J.H. Vanillin, a potential agent to prevent biofouling of reverse osmosis membrane. Biofouling 2010, 26, 667-672.

37. Kumar, S.S.; Ghosh, A.; Devasagayam, T.P.A.; Chauhan, P.S. Effect of vanillin on methylene blue plus light-induced single-strand breaks in plasmid pBR322 DNA. Mutat. Res. Genet. Toxicol. Environ. Mutagen. 2000, 469, 207-214.

38. Aruoma, O.I.; Evans, P.J.; Kaur, H.; Sutcliffe, L.; Halliwell, B. An evaluation of the antioxidant and potential pro-oxidant properties of food-additives and of trolox-c, vitamin-e and probucol. Free Rad. Res. Commun. 1990, 10, 143-157.

39. Utsumi, H.; Fujii, K.; Irie, H.; Furusaki, A.; Nitta, I. Crystal structure of p-coumaric acid. Bull. Chem. Soc. Jpn. 1967, 40, 426-426

40. Castelluccio, C.; Paganga, G.; Melikian, N.; Bolwell, G.P.; Pridham, J.; Sampson, J.; Riceevans, C. Antioxidant potential of intermediates in phenylpropanoid metabolism in higher-plants. FEBS Lett. 1995, 368, 188-192.

41. Sharma, R.D. Isoflavones and hypercholesterolemia in rats. Lipids 1979, 14, 535-540.

42. Gaberscik, A.; Voncina, M.; Trost, T.; Germ, M.; Bjorn, L.O. Growth and production of buckwheat (Fagopyrum esculentum) treated with reduced, ambient, and enhanced UV-B radiation. J. Photochem. Photobiol. B-Biol. 2002, 66, 30-36.

43. Rozema, J.; Bjorn, L.O.; Bornman, J.F.; Gaberscik, A.; Hader, D.P.; Trost, T.; Germ, M.; Klisch, M.; Groniger, A.; Sinha, R.P.; Lebert, M.; He, Y.Y.; Buffoni-Hall, R.; de Bakker, N.V.J.; van de Staaij, J.; Meijkamp, B.B. The role of UV-B radiation in aquatic and terrestrial ecosystems - an experimental and functional analysis of the evolution of UV-absorbing compounds. J. Photochem. Photobiol. B-Biol. 2002, 66, 2-12.

44. Korkmaz, A.; Kolankaya, D. Protective Effect of Rutin on the Ischemia/Reperfusion Induced Damage in Rat Kidney. J. Surg. Res. 2010, 164, 309-315.

45. Abeywardena, M.Y.; Head, R.J. Dietary polyunsaturated fatty acid and antioxidant modulation of vascular dysfunction in the spontaneously hypertensive rat. Prostagland. Leuk. Essent. Fatty Acids 2001, 65, 91-97.

46. Wojcicki, J.; Barcewwiszniewska, B.; Samochowiec, L.; Rozewicka, L. Extractum-fagopyri reduces atherosclerosis in high-fat diet fed rabbits. Pharmazie 1995, 50, 560-562.

47. Bingjiang, L.; Wei, M.; Dan, L. Photoprotective effects of ferulic on human keratinocyte HaCaT cells: Proteomic identification of proteins associated with cutaneous cancer. J. Invest. Dermatol. 2010, 130, 796.

48. Zhang, L.W.; Al-Suwayeh, S.A.; Hsieh, P.W.; Fang, J.Y. A comparison of skin delivery of ferulic acid and its derivatives: Evaluation of their efficacy and safety. Int. J. Pharm. 2010, 399, 44-51.

49. Yabe, T.; Hirahara, H.; Harada, N.; Ito, N.; Nagai, T.; Sanagi, T.; Yamada, H. Ferulic acid induces neural progenitor cell proliferation in vitro and in vivo. Neuroscience 2010, 165, 515-524.

50. de Boer, V.C.J.; Dihal, A.A.; van der Woude, H.; Arts, I.C.W.; Wolffram, S.; Alink, G.M.; Rietjens, I.; Keijer, J.; Hollman, P.C.H. Tissue distribution of quercetin in rats and pigs. J. Nutr. 2005, 135, 1718-1725. 
51. Cushnie, T.P.T.; Lamb, A.J. Antimicrobial activity of flavonoids. Int. J. Antimicrob. Agents 2005, 26, 343-356.

52. Seufi, A.M.; Ibrahim, S.S.; Elmaghraby, T.K.; Hafez, E.E. Preventive effect of the flavonoid, quercetin, on hepatic cancer in rats via oxidant/antioxidant activity: Molecular and histological evidences. J. Exp. Clin. Cancer Res. 2009, 28, 1-8

53. Kaindl, U.; Eyberg, I.; Rohr-Udilova, N.; Heinzle, C.; Marian, B. The dietary antioxidants resveratrol and quercetin protect cells from exogenous pro-oxidative damage. Food Chem. Toxicol. 2008, 46, 1320-1326.

54. Orsolic, N.; Knezevic, A.H.; Sver, L.; Terzic, S.; Basic, I. Immunomodulatory and antimetastatic action of propolis and related polyphenolic compounds. J. Ethnopharmacol. 2004, 94, 307-315.

55. Arts, I.C.W.; Hollman, P.C.H. Polyphenols and disease risk in epidemiologic studies. Am. J. Clin. Nutr. 2005, 81, 317S-325S.

56. Knekt, P.; Kumpulainen, J.; Jarvinen, R.; Rissanen, H.; Heliovaara, M.; Reunanen, A.; Hakulinen, T.; Aromaa, A. Flavonoid intake and risk of chronic diseases. Am. J. Clin. Nutr. 2002, 76, 560-568.

57. Benkovic, V.; Kopjar, N.; Knezevic, A.H.; Dikic, D.; Basic, I.; Ramic, S.; Viculin, T.; Knezevic, F.; Orsolic, N. Evaluation of radioprotective effects of propolis and quercetin on human white blood cells in vitro. Biol. Pharm. Bull. 2008, 31, 1778-1785.

58. Rahman, M.M.; Bak, I.; Das, D.K. Effectiveness of Resveratrol Against Cardiovascular Disease. Mini-Rev. Org. Chem. 2010, 7, 256-261.

59. Toklu, H.Z.; Sehirli, O.; Ersahin, M.; Suleymanoglu, S.; Yiginer, O.; Emekli-Alturfan, E.; Yarat, A.; Yegen, B.C.; Senser, G. Resveratrol improves cardiovascular function and reduces oxidative organ damage in the renal, cardiovascular and cerebral tissues of two-kidney, one-clip hypertensive rats. J. Pharm. Pharmacol. 2010, 62, 1784-1793.

60. Chicoine, L.G.; Stewart, J.A.; Lucchesi, P.A. Is Resveratrol the Magic Bullet for Pulmonary Hypertension? Hypertension 2009, 54, 473-474.

61. Tiwari, V.; Sharma, S.; Kulkarni, S.K.; Chopra, K. Amelioration of oxidative stress and renal dysfunction by insulin and its combination with curcumin or resveratrol: Role of TGF-beta. Indian J. Pharmacol. 2008, 40, 90-90

62. Thandapilly, S.J.; Wojciechowski, P.; Behbahani, J.; Louis, X.L.; Yu, L.P.; Juric, D.; Kopilas, M.A.; Anderson, H.D.; Netticadan, T. Resveratrol Prevents the Development of Pathological Cardiac Hypertrophy and Contractile Dysfunction in the SHR Without Lowering Blood Pressure. Am. J. Hypertens. 2010, 23, 192-196.

63. Khalil, A.; Berrougui, H. Mechanism of action of resveratrol in lipid metabolism and atherosclerosis. Clin. Lipidol. 2009, 4, 527-531.

64. Kaeberlein, M. Resveratrol and rapamycin: are they anti-aging drugs? Bioessays 2010, 32, 96-99.

65. Wagner, C.; Fachinetto, R.; Corte, C.L.D.; Brito, V.B.; Severo, D.; Dias, G.; Morel, A.F.; Nogueira, C.W.; Rocha, J.B.T. Quercitrin, a glycoside form of quercetin, prevents lipid peroxidation in vitro. Brain Res. 2006, 1107, 192-198.

66. Jung, M.; Park, M. Acetylcholinesterase inhibition by flavonoids from agrimonia pilosa. Molecules 2007, 12, 2130-2139.

67. Materska, M.; Perucka, I. Antioxidant activity of the main phenolic compounds isolated from hot pepper fruit (Capsicum annuum L.). J. Agric. Food Chem. 2005, 53, 1750-1756. 
68. Davis, R.A.; Simpson, M.M.; Nugent, R.B.; Carroll, A.R.; Avery, V.M.; Rali, T.; Chen, H.; Qurallo, B.; Quinn, R.J. Pim2 inhibitors from the Papua New Guinean plant Cupaniopsis macropetala. J. Nat. Prod. 2008, 71, 451-452.

69. Ibrahim, N.A.; El-Seedi, H.R.; Mohammed, M.M.D. Phytochemical investigation and hepatoprotective activity of Cupressus sempervirens L. leaves growing in Egypt. Nat. Prod. Res. 2007, 21, 857-866.

70. Liu, Y.; Murakami, N.; Ji, H.; Abreu, P.; Zhang, S. Antimalarial flavonol glycosides from Euphorbia hirta. Pharm. Biol. 2007, 45, 278-281.

71. Fukai, T.; Sakagami, H.; Toguchi, M.; Takayama, F.; Iwakura, I.; Atsumi, T.; Ueha, T.; Nakashima, H.; Nomura, T. Cytotoxic activity of low molecular weight polyphenols against human oral tumor cell lines. Anticancer Res. 2000, 20, 2525-2536.

72. Dai, J.; Mumper, R.J. Plant Phenolics: Extraction, Analysis and Their Antioxidant and Anticancer Properties. Molecules 2010, 15, 7313-7352.

73. Naczk, M.; Shahidi, F. Extraction and analysis of phenolics in food. J. Chromatogr. A 2004, 1054, 95-111.

74. Stalikas, C.D. Extraction, separation, and detection methods for phenolic acids and flavonoids. $J$. Sep. Sci. 2007, 30, 3268-3295.

75. Kartsova, L.A.; Alekseeva, A.V. Chromatographic and Electrophoretic Methods for Determining Polyphenol Compounds. J. Anal. Chem. 2008, 63, 1024-1033.

76. Yang, L.; Jiang, J.G.; Li, W.F.; Chen, J.; Wang, D.Y.; Zhu, L. Optimum extraction Process of polyphenols from the bark of Phyllanthus emblica L. based on the response surface methodology. J. Sep. Sci. 2009, 32, 1437-1444.

77. Cork, S.J.; Krockenberger, A.K. Methods and pitfalls of extracting condensed tannins and other phenolics from plants - insights from investigations on eucalyptus leaves. J. Chem. Ecol. 1991, 17, 123-134.

78. Khanna, S.K.; Viswanat, P.N.; Krishnan, P.S.; Sanwal, G.G. Extraction of total phenolics in presence of reducing agents. Phytochemistry 1968, 7, 1513-1517

79. Ragazzi, E.; Veronese, G. Quantitative-analysis of phenolic compounds after thin-layer chromatographic separation. J. Chromatogr. 1973, 77, 369-375.

80. Rodriguez-Arcos, R.C.; Smith, A.C.; Waldron, K.W. Effect of storage on wall-bound phenolics in green asparagus. J. Agric. Food Chem. 2002, 50, 3197-3203.

81. Barroso, C.G.; Rodriguez, M.C.; Guillen, D.A.; PerezBustamante, J.A. Analysis of low molecular mass phenolic compounds, furfural and 5-hydroxymethylfurfural in Brandy de Jerez by highperformance liquid chromatography diode array detection with direct injection. J. Chromatogr. A 1996, 724, 125-129.

82. Dekic, S.; Milosavljevic, S.; Vajs, V.; Jovic, S.; Petrovic, A.; Nikicevic, N.; Manojlovic, V.; Nedovic, V.; Tesevic, V. Trans- and cis-resveratrol concentration in wines produced in Serbia. J. Serb. Chem. Soc. 2008, 73, 1027-1037.

83. Kivilompolo, M.; Oburka, V.; Hyotylainen, T. Comprehensive two-dimensional liquid chromatography in the analysis of antioxidant phenolic compounds in wines and juices. Anal. Bioanal. Chem. 2008, 391, 373-380. 
84. Benova, B.; Hajek, T. Utilization of coulometric array detection in analysis of beverages and plant extracts. In 5th Symposium by Nordic Separation Science Society; Kaljurand, M., Ed.; Elsevier Science Bv: Amsterdam, The Netherlands, 2010; Volume 2, pp. 92-100.

85. Krafczyk, N.; Glomb, M.A. Characterization of phenolic compounds in rooibos tea. J. Agric. Food Chem. 2008, 56, 3368-3376.

86. Kahoun, D.; Rezkova, S.; Veskrnova, K.; Kralovsky, J.; Holcapek, M. Determination of phenolic compounds and hydroxymethylfurfural in meads using high performance liquid chromatography with coulometric-array and UV detection. J. Chromatogr. A 2008, 1202, 19-33.

87. Jouki, M.; Khazaei, N. Compare of extraction of phenolic compounds from Pistacia atlantica in different solvents. In Advances in Biomedical Research, Proceedings; Anninos, P., Rossi, M., Pham, T.D., Falugi, C., Bussing, A., Koukkou, M., Eds.; World Scientific and Engineering Acad and Soc: Athens, Greece, 2010; pp. 361-365.

88. Turkmen, N.; Velioglu, Y.S.; Sari, F.; Polat, G. Effect of extraction conditions on measured total polyphenol contents and antioxidant and antibacterial activities of black tea. Molecules 2007, 12, 484-496.

89. Krygier, K.; Sosulski, F.; Hogge, L. Free, esterified, and insoluble-bound phenolic-acids .1. Extraction and purification procedure. J. Agric. Food Chem. 1982, 30, 330-334.

90. Rababah, T.M.; Banat, F.; Rababah, A.; Ereifej, K.; Yang, W. Optimization of Extraction Conditions of Total Phenolics, Antioxidant Activities, and Anthocyanin of Oregano, Thyme, Terebinth, and Pomegranate. J. Food Sci. 2010, 75, C626-C632.

91. Rodrigues, S.; Pinto, G.A.S.; Fernandes, F.A.N. Optimization of ultrasound extraction of phenolic compounds from coconut (Cocos nucifera) shell powder by response surface methodology. Ultrason. Sonochem. 2008, 15, 95-100.

92. Gribova, N.Y.; Filippenko, T.A.; Nikolaevskii, A.N.; Belaya, N.I.; Tsybulenko, A.A. Optimization of Conditions for the Extraction of Antioxidants from Solid Parts of Medicinal Plants. J. Anal. Chem. 2008, 63, 1034-1037.

93. Bors, W.; Michel, C. Chemistry of the antioxidant effect of polyphenols. In Alcohol and Wine Health and Disease; Das, D.K., Ursini, F., Eds.; New York Acad Sciences: New York, NY, USA, 2002; Volume 957, pp. 57-69.

94. Dragovic-Uzelac, V.; Levaj, B.; Mrkic, V.; Bursac, D.; Boras, M. The content of polyphenols and carotenoids in three apricot cultivars depending on stage of maturity and geographical region.

Food Chem. 2007, 102, 966-975.

95. Long, G.L.; Winefordner, J.D. Limit of Detection. Anal. Chem. 1983, 55, A712-A724.

Sample Availability: Samples of protocatechuic acid, 4-aminobenzoic acid, chlorogenic acid, caffeic acid, vanillin, $p$-coumaric acid, rutin, ferulic acid, quercetin, resveratrol, quercitrin are available from the authors.

(C) 2011 by the authors; licensee MDPI, Basel, Switzerland. This article is an open access article distributed under the terms and conditions of the Creative Commons Attribution license (http://creativecommons.org/licenses/by/3.0/). 